\title{
Validation of the Brazilian version of the pediatric outcomes data collection instrument: a cross-sectional evaluation in children and adolescents with juvenile idiopathic arthritis
}

Felipe Alves do Monte ${ }^{1 *}$, Moacir Novaes Lima Ferreira', Kátia Cristina Lima Petribu', Nair Cristina Almeida ${ }^{1}$, José Benjamim Gomes ${ }^{1}$, Maria Helena Mariano ${ }^{1}$, Zelina Barbosa Mesquita², Diego Montarroyos Simões ${ }^{1}$, André Furtado de Ayalla Rodrigues ${ }^{1}$ and Mariana Alves Nogueira Souza ${ }^{1}$

\begin{abstract}
Background: There is a lack of health-related quality of life (HRQOL) questionnaires to evaluate pediatric musculoskeletal diseases in Brazil. The Pediatric Outcome Data Collection Instrument (PODCI) is widely used elsewhere for pediatric patients with musculoskeletal disorders, but it has not been fully validated in Brazil. Validation of the PODCl in the Brazilian Portuguese language is important to improve the assessment of pediatric patients with musculoskeletal diseases and to compare Brazilian study results with results from the international literature. This study aimed to analyze the test-re-test reliability and the convergent validity indicators for the quality of life scores obtained by application of the PODCI to children and adolescents with juvenile idiopathic arthritis (JIA).
\end{abstract}

Methods: The PODCl underwent translation, transcultural adaptation, and field testing. Fifty-seven children and adolescents with JIA were administered the PODCl questionnaire. The Child Health Questionnaire - Parent Form 28 (CHQ PF-28) was used as the gold standard. Pain scales were employed, clinical examinations were performed, and laboratory inflammatory activity tests were conducted.

Results: The three versions of the PODCl exhibited good internal consistency (Cronbach's alpha coefficient >0.70), good reproducibility $(p<0.05)$, and good correlation compared with the gold standard $(\mathrm{CHQ})$, as shown by a Spearman coefficient $(\mathrm{Rho})>0.40(\mathrm{p}<0.05)$.

Conclusions: The PODCI was validated in patients with JIA in Brazil. This questionnaire was found to be valid, precise, and reliable. It can be successfully applied in research conducted by healthcare professionals who work with children and adolescents with musculoskeletal system disorders.

Keywords: Quality of life, Questionnaires, Musculoskeletal diseases, Children, Adolescents, Validation studies, Brazil

\footnotetext{
* Correspondence: falvesmonte@gmail.com

'Clinical Research Unit of Oswaldo Cruz University Hospital and Pernambuco, Cardiologic Emergency at Pernambuco University, Rua Arnóbio Marques, 310, Santo Amaro, Recife, PE 52011-240, Brazil

Full list of author information is available at the end of the article
} 


\section{Background}

Advances in health sciences have improved the methodologies used to analyze the outcomes of clinical and surgical treatments. Measurements, such as health-related quality of life (HRQOL), functional capacity, pain scores, and personal satisfaction scales, have been widely employed because they capture the concerns of individuals and provide a measure of the burden of disease for individuals and of the effects of treatment.

Health status questionnaires such as the Child Health Questionnaire (CHQ) [1], the Pediatric Quality of Life Inventory (PedsQL) [2] and the Pediatric Outcome Data Collection Instrument (PODCI) [3] are used worldwide in pediatric patients with a variety of acute and chronic conditions (e.g., asthma, sleep apnea, neuromuscular diseases) and also in those with musculoskeletal diseases. CHQ and PedsQL monitor generic health status while the PODCI covers functionality of special significance to individuals with musculoskeletal impairments such as orthopedic and rheumatologic conditions [4-12].

Most HRQOL questionnaires are available in English. Whenever an adequately validated measurement assessing a given condition exists in any language, it is timesaving and economically advantageous to validate an existing instrument in a different language rather than develop a new instrument [13], and guidelines are available to establish the transcultural equivalence of such questionnaires $[14,15]$.

There are several reasons to validate the PODCI in Brazil. These include its wide range of functional measurements, its use in international publications [4-11], the multidisciplinary construction of the questionnaire, and the possibility of its use by professionals in different areas of research. It is a sensitive instrument for detecting changes in the health states of individuals [3] and is considered the most comprehensive instrument for use in children, adolescents and caregivers $[12,16]$. Therefore, the aim of this study was to analyze and validate the reproducibility and the convergent indicators of QOL scores obtained by the PODCI in children and adolescents with juvenile idiopathic arthritis (JIA) in Brazil.

\section{Methods}

The study was approved by the Human Research Ethics Committee of Oswaldo Cruz University Hospital/ Pernambuco Cardiologic Emergency Room of Pernambuco University (protocol - Research Ethics Committee: no. 10/2010). The study population comprised patients attending the pediatric rheumatology outpatient clinic of the Professor Fernando Figueira Institute of Integral Medicine.

A convenience sample was used and the size was estimated by assuming a Spearman's correlation coefficient of 0.60 from the results of a previous study [17] in which PODCI measurements were correlated with those of the
CHQ Parent Form-28 (CHQ PF-28). Furthermore, the sample size was supported by a previous study of the evaluation of the PODCI by Daltroy et al. [3]. Hence, assuming a statistical power of $80 \%$ and a significance level of $95 \%$, the minimum sample size was estimated to be 19 JIA patients. The sample consisted of children and adolescents of both sexes who were diagnosed with JIA according to the International League of Associations for Rheumatology diagnostic criteria [18-20], and had no other physical and/or mental comorbid conditions.

The patients' caregivers were informed of the aims of the study and of the possible risks and benefits, and were asked to sign an informed consent form (participation was voluntary). The PODCI and CHQ PF-28 questionnaires were completed by the patients' caregivers between September and December 2010. An experienced rheumatologist in our group assessed disease activity as one of four levels: (0) no activity, (1) mild, (2) moderate, and (3) severe [21].

Data on HRQOL were collected by administration of the PODCI and the CHQ PF-28. Three versions of PODCI questionnaires were used: Q1 was given to parents or caregivers of patients who were 2 to 10 years old; Q2 was given to parents or caregivers of individuals who were 11 to 18 years old; and Q3 was given to patients who were 11 to 18 years old. There were no major differences among the three versions of the PODCI. There were a few modifications to adapt the questionnaires to activities related to the age group and to the person interviewed (patient or caregiver).

The PODCI questionnaire consisted of 48 items encompassing six domains: 1 ) function of the upper limbs (eight items); 2) transfer and basic mobility (11 items); 3) sports and physical function (21 items); 4) comfort and pain (three items); 5) satisfaction with physical condition (five items); and 6) global function. Global function was represented by the mean scores of the first four domains listed above. Translation, transcultural adaptation, and validation of the PODCI followed the stages recommended by the American Academy of Orthopedic Surgeons (AAOS) $[15,22]$ : forward translation, backward translation, evaluation by an expert committee, pre-testing, and field testing.

The CHQ PF-28 consisted of 14 domains. This instrument was applied by means of interviews with the patients' caregivers. The physical function domain (three items) was used as the gold standard following the original process of the PODCI validation recommended by the AAOS/Pediatric Orthopedic Society of North America $[3,22]$.

The dependent variables were the scores obtained for each separate domain and one PODCI global measurement of quality of life. Scores were graded between 0 and 100 , where 0 was rated the worst and 100 was rated the best. The independent variables were functional dimension 
Table 1 Scores of the PODCI and the CHQ PF-28 physical function domains in children and adolescents with juvenile idiopathic arthritis

\begin{tabular}{|c|c|c|c|c|c|c|}
\hline Domain & $\mathbf{n}$ & Mean & Standard deviation & Median & Minimum & Maximum \\
\hline \multicolumn{7}{|l|}{ Q1 - Children } \\
\hline Function of the upper limbs (PODCI) & 31 & 78.36 & 20.88 & 83.33 & 33.33 & 100.00 \\
\hline Transfer and basic mobility (PODCI) & 30 & 78.69 & 25.04 & 89.86 & 15.97 & 100.00 \\
\hline Sports and physical function (PODCl)* & 31 & 60.62 & 29.48 & 66.84 & 2.78 & 100.00 \\
\hline Comfort and pain (PODCl)* & 31 & 58.99 & 19.88 & 56.00 & 20.33 & 100.00 \\
\hline Happiness/satisfaction (PODCI) & 22 & 65.59 & 29.94 & 72.50 & 0.00 & 100.00 \\
\hline Global function (PODCI) & 30 & 69.03 & 18.69 & 75.81 & 29.67 & 91.67 \\
\hline Physical function (CHQ-PF 28) & 32 & 56.25 & 36.11 & 66.67 & 0.00 & 100.00 \\
\hline \multicolumn{7}{|l|}{ Q2 - Adolescents (self-reported) } \\
\hline Function of the upper limbs (PODCI) & 23 & 91.30 & 12.04 & 95.83 & 58.33 & 100.00 \\
\hline Transfer and basic mobility (PODCI) & 23 & 85.56 & 19.01 & 93.94 & 36.55 & 100.00 \\
\hline Sports and physical function (PODCl)* & 23 & 57.18 & 28.50 & 50.00 & 10.22 & 100.00 \\
\hline Comfort and pain (PODCl)* & 23 & 64.40 & 13.48 & 66.67 & 31.00 & 82.63 \\
\hline Happiness/satisfaction (PODCI) & 23 & 75.65 & 22.38 & 80.00 & 15.00 & 100.00 \\
\hline Global function (PODCl)* & 23 & 74.61 & 13.74 & 73.42 & 45.82 & 92.20 \\
\hline \multicolumn{7}{|l|}{ Q3 - Adolescents (reported by caregivers) } \\
\hline Function of the upper limbs (PODCI) & 25 & 81.07 & 24.22 & 95.24 & 20.83 & 100.00 \\
\hline Transfer and basic mobility (PODCI) & 24 & 78.67 & 22.21 & 80.97 & 13.64 & 100.00 \\
\hline Sports and physical function (PODCl) & 25 & 49.08 & 28.96 & 40.72 & 6.82 & 100.00 \\
\hline Comfort and pain (PODCI) & 25 & 63.16 & 18.86 & 66.67 & 22.67 & 92.10 \\
\hline Happiness/satisfaction (PODCl)* & 24 & 61.87 & 27.81 & 62.5 & 10.00 & 100.00 \\
\hline Global function (PODCl)* & 24 & 68.24 & 16.33 & 68.91 & 37.48 & 92.70 \\
\hline Physical function (CHQ PF-28) & 24 & 42.36 & 36.29 & 33.33 & 0.00 & 100.00 \\
\hline
\end{tabular}

$\mathrm{PODCl}=$ Pediatric Outcome Data Collection Instrument; CHQ PF-28 = Child Health Questionnaire - Parent Form 28.

*Data follow a normal distribution.

scores obtained by means of the CHQ PF-28, the Faces Pain Scale [23], and the visual analog scale [24,25], the disease activity score, the number of active joints, and the number of limited joints. The CHQ PF-28 scores were graded between 0 and 100. The number of active joints and limited joints were identified by the attending physician. Joints were rated as limited when they exhibited some motion deficiency and were rated as active when they were swollen or movement was limited by pain.
Patients were divided into two categories according to age range: 2 to 10 years old (children) and 11 to 18 years old (adolescents).

Test-re-test reliability of the PODCI was obtained after an interval of 24-48 hours, and the intraclass correlation coefficient was determined. The convergent validity coefficient was estimated by comparing the $\mathrm{CHQ}$ physical function score and the PODCI final score. The internal consistency of the instrument was established by

Table 2 Intraclass correlation coefficient (IC) of data collected during first and second administration of the PODCI

\begin{tabular}{|c|c|c|c|c|c|c|}
\hline \multirow[t]{3}{*}{ Domain } & \multirow{2}{*}{\multicolumn{2}{|c|}{$\begin{array}{c}\text { Q1 } \\
\text { Children }\end{array}$}} & \multicolumn{2}{|c|}{ Q2 } & \multicolumn{2}{|c|}{ Q3 } \\
\hline & & & \multicolumn{2}{|c|}{ Adolescents (self-report) } & \multicolumn{2}{|c|}{ Adolescents (reported by caregivers) } \\
\hline & IC & $\mathbf{p}$ & IC & $\mathbf{p}$ & IC & $\mathbf{p}$ \\
\hline Physical function of the upper limb & 0.89 & $<0.001$ & 0.97 & $<0.001$ & 0.86 & $<0.001$ \\
\hline Transfer and basic mobility & 0.97 & $<0.001$ & 0.81 & $<0.001$ & 0.04 & 0.449 \\
\hline Sports and physical function & 0.97 & $<0.001$ & 0.97 & $<0.001$ & 0.60 & 0.014 \\
\hline Pain and comfort & 0.82 & $<0.001$ & 0.59 & 0.016 & 0.18 & 0.274 \\
\hline Happiness/satisfaction & 0.69 & 0.001 & 0.53 & 0.032 & 0.68 & 0.006 \\
\hline
\end{tabular}


Cronbach's alpha coefficient $(\alpha)$, where 0.70 was rated sufficient for validation studies [3].The significance level was established at 5\% to reject the null hypothesis in each analysis.

Data were entered into a data file using EpiData v.3.1 software (EpiData, Odense, Denmark); electronic procedures were used to control data entry. Data analysis was performed using the statistical package SPSS for Windows v. 10 (IBM Corp., Armonk, NY, USA); descriptive (i.e., frequency distribution, central tendency measures, dispersion, and amplitude) and inductive statistical procedures were employed.

Dispersion graphics were used to determine the presence of outliers, which were excluded from the analysis. The Shapiro-Wilk test was used to analyze the normal distribution.

\section{Results}

The validity study effectively assessed 57 patients (32 children and 25 adolescents). The mean age was 10.1 years old (standard deviation (SD), 4.3), 71.4\% were female, and polyarticular JIA was the most frequent disease subtype (33.3\%). The reproducibility study included 28 individuals (16 children and 12 adolescents). The mean age was 10.2 years old (SD, 3.9), and 64.3\% were female. Descriptive data of the scores of the three versions of the PODCI and of the CHQ PF-28 physical function domain are presented in Table 1.

The scores of some of the questionnaire domains could not be calculated because they had "lost data" according to the criteria recommended by the AAOS [23]. The number of lost domains varied between $0 \%$ and $8 \%$ in the three versions of the PODCI; the happiness/satisfaction domain, which was answered by the patients, exhibited a $50 \%$ data loss.

All three PODCI versions exhibited good internal consistency. The pediatric version had Cronbach's $\alpha=0.9$, whereas adolescents who self-reported their answers and whose caregivers answered the questions had $\alpha$ values of 0.82 and 0.72 , respectively.

Table 2 shows the results of the reproducibility of each domain of the three versions of the PODCI. The testre-test intraclass correlation coefficient concordance varied between 0.69 and 0.97 in Q1, between 0.53 and 0.97 in Q2, and between 0.04 and 0.86 in Q3. All three versions exhibited good reproducibility in most questionnaire domains.

Good correlation was observed (Rho $\geq 0.50$ ) between the CHQ PF-28 physical function domain scores and global function in all three versions of the PODCI questionnaire (Table 3).

An inverse correlation was observed between the numbers of active and limited joints and the PODCI and CHQ PF-28 questionnaire scores (Table 4).
Table 3 Spearman's correlation coefficients (Rho) comparing the CHQ PF-28 questionnaire physical function domains and global function in the three versions of the PODCI questionnaire

\begin{tabular}{lcc}
\hline PODCI (global function) $\times$ CHQ PF-28 & Rho & p value \\
\hline Q1 - Children & 0.79 & $<0.01$ \\
Q2 - Adolescents (self-reported) & 0.67 & $<0.01$ \\
Q3 - Adolescents (reported by caregivers) & 0.50 & 0.02 \\
\hline
\end{tabular}

\section{Discussion}

The main finding in this study was that all three versions of the PODCI exhibited excellent internal consistency and good reproducibility compared with the gold standard (CHQ); thus, the PODCI demonstrated a high level of precision. The psychometric properties were similar to those observed in the original PODCI elaboration and validation study [3]. A recent study validating the PODCI in Korean children observed that items in the pain/comfort and personal satisfaction domains exhibited low internal consistency [26], which was not observed in our study.

Response rates of only $50 \%$ in the happiness/satisfaction domain may have resulted from difficulties in understanding the questions in this domain during the interview, and the usefulness of this domain is questionable. However, this domain is not included in the measurement of "global function", so missing data should not compromise the use and validity of the instrument.

In our study, the happiness/personal satisfaction domain exhibited low reproducibility in some versions and for some items of the questionnaire. This finding was also observed in a study of United States' subjects [3]. Additionally, an item assessing sports activities at school, "How often in the last week did your child participate in gym/recess?", exhibited low reproducibility. This was probably a result of the similarity between two possible

Table 4 Spearman correlation coefficients (Rho) comparing the PODCI global function scores, the CHQ PF-28 physical function scores, and the numbers of active and limited joints

\begin{tabular}{llllll}
\hline Questionnaires & \multicolumn{2}{c}{$\begin{array}{c}\text { Number of } \\
\text { active joints }\end{array}$} & & \multicolumn{2}{c}{$\begin{array}{c}\text { Number of } \\
\text { limited joints }\end{array}$} \\
\cline { 2 - 3 } & Rho & p & & Rho & p \\
\hline Q1 - Children & & & & & \\
\hline PODCl (global function) & -0.56 & $<0.01$ & & -0.41 & 0.03 \\
CHQ PF-28 (physical function) & -0.63 & $<0.01$ & & -0.49 & $<0.01$ \\
\hline Q2 - Adolescents (self-reported) & & & & & \\
\hline PODCl (global function) & -0.51 & 0.01 & -0.56 & $<0.01$ \\
\hline Q3 - Adolescents (reported by caregivers) & & & & \\
\hline PODCl (global function) & -0.48 & 0.03 & & -0.57 & $<0.01$ \\
CHQ PF-28 (physical function) & -0.32 & 0.16 & & -0.58 & $<0.01$ \\
\hline
\end{tabular}


answers, "school is not in session" and "my child does not attend school". In both situations, items exhibiting low reproducibility were not statistically significant.

Assis et al. [27] previously validated the PODCI only in parents or caregivers in Brazil and observed the sensitivity of the PODCI for detecting changes in the health states of ill individuals. However, they did not validate this instrument for its capacity to detect QOL in a cross-sectional sample, and did not evaluate its precision.

As in the original PODCI validation study, the CHQ PF-28 physical function was used as the gold standard [3] to assess convergent validity. In our study, the validity of the PODCI translated into Portuguese was compared with the CHQ PF-28 physical function domain. All items exhibited good correlations with the gold standard. The inverse correlation between the number of affected joints, the PODCI, and the gold standard questionnaire scores support its convergent validity.

The PODCI measures cross-sectional or longitudinal QOL in individuals which distinguishes the PODCI from other generic questionnaires [3,26,27]. The sensitivity of the PODCI to clinical changes [3] makes it a valuable instrument [28], and the sensitivity of all three PODCI versions to changes in Brazilian patients was verified. Finally, PODCI reference values for healthy Brazilian individuals have not been established. Most of the generic questionnaires used in patients with JIA cannot be used for longitudinal assessments, making them unsuitable for evaluating treatment outcomes, whereas the PODCI is applicable for such assessments. However, the PODCI needs to be further validated in Brazil in longitudinal studies of treatment outcome.

\section{Conclusions}

The PODCI was translated into Portuguese, and adapted and validated for use in Brazilian children and adolescents with JIA and their caretakers. This new questionnaire was determined to be valid, precise, and reliable and should be useful for studies in children and adolescents with musculoskeletal disorders.

\section{Abbreviations \\ HRQOL: Health-related quality of life; CHQ: Child health questionnaire; PedsQL: Pediatric quality of life; PODCl: Pediatric outcome data collection instrument; JIA: Juvenile idiopathic arthritis; CHQ PF-28: Child health questionnaire - parent form 28; AAOS: American academy of orthopedic surgeons.}

\section{Competing interests}

The authors declare that they have no competing interests.

\section{Authors' contributions}

FAM conceptualized and designed the study, analyzed the data and drafted the manuscript. FAM, MNLF, KCLP, NCA, JBG, MHM, ZBM and MHL provided comments and revisions to the manuscript. FAM and NCA participated in the translation and adaptation of the questionnaires. ZBM performed the clinical evaluation of all patients with JIA. FAM, DMS, AFAR and MANS collected and analyzed the data. All authors read and approved the final manuscript.

\section{Authors' information}

FAM, MNLF, KCLP, NCA, JBG, MHM, DMS, AFAR and MANS are researchers from the Clinical Research Unit, Oswaldo Cruz University Hospital/ Pernambuco Cardiologic Emergency Room of Pernambuco University. ZBM is a doctor working at the Professor Fernando Figueira Institute of Integral Medicine.

\section{Acknowledgments}

We thank Carla Menêses Santos and Mauro Barros for statistical support Fabia Lima for supporting the transcultural adaptation process of the questionnaire, and Dr Matthew Liang of Harvard Medical School for his suggestions on the manuscript.

The study was supported by the National Council of Scientific and Technological Development of the Brazilian government [process number 559618/2009-3]

\section{Author details}

${ }^{1}$ Clinical Research Unit of Oswaldo Cruz University Hospital and Pernambuco, Cardiologic Emergency at Pernambuco University, Rua Arnóbio Marques, 310, Santo Amaro, Recife, PE 52011-240, Brazil. Pediatric Rheumatology Unit, Professor Fernando Figueira Institute of Integral Medicine, Rua dos Coelhos, 300, Coelhos, Recife, PE 50070-550, Brazil.

Received: 5 March 2013 Accepted: 28 October 2013

Published: 30 October 2013

\section{References}

1. Landgraf JM, Abetz L, Ware JE: Child Health Questionnaire (CHQ): A User's Manual. 2nd edition. Boston: Health Act; 1999.

2. Varni JW, Burwinkle TM, Seid M: The PedsQL 4.0 as a school population health measure: feasibility, reliability, and validity. Qual Life Res 2006, 15:203-215

3. Daltroy LH, Liang MH, Fossel AH, Golberg MJ, The Pediatric Outcomes Instrument Development Group: The POSNA pediatric musculoskeletal functional health questionnaire: report on reliability, validity, and sensitivity to change. J Pediatr Orthop 1998, 18:561-571.

4. Ugwonali OF, Lomas G, Hyman JE, Lee FY, Vitale MG, Roye DP Jr: Effect of bracing on the quality of life of adolescents with idiopathic scoliosis. Spine J 2004, 4:254-260.

5. Ramachandran M, Ward K, Brown RR, Munns CF, Cowell CT, Little DG: Intravenous biphosphonate therapy for traumatic osteonecrosis of the femoral head in adolescents. J Bone Joint Surg Am 2007, 89:1727-1734.

6. Zwick EB, Kraus T, Maizen C, Steinwender G, Linhart WE: Comparison of Ponseti versus surgical treatment for idiopathic clubfoot: a short-term preliminary report. Clinic Orthop Relat Res 2009, 467:2668-2676.

7. Henderson ER, Pepper AM, Maruland G, Binitie OT, Cheong D, Letson GD: Outcome of lower-limb preservation with an expandable endoprosthesis after bone tumor resection in children. J Bone Joint Surg Am 2012 94:537-547.

8. Snyder AR, Martinez JC, Bay RC, Parsons JT, Sauers EL, Valovich McLeod TC: Health-related quality of life differs between adolescent athletes and adolescent nonathletes. J Sport Rehabil 2010, 19:237-248.

9. Kunkel S, Eismann E, Cornwall R: Utility of the pediatric outcomes data collection instrument for assessing acute hand and wrist injuries in children. J Pediatr Orthop 2011, 31:767-772.

10. Spencer HT, Bowen RE, Caputo K, Green TA, Lawrence JF: Bone mineral density and functional measures in patients with arthrogryposis. J Pediatr Orthop 2010, 30:514-518.

11. Kubiak EN, Egol KA, Scher D, Wasserman B, Fedman D, Koval KJ: Operative treatment of tibial fractures in children: are elastic stable intramedullary nails an improvement over external fixation? J Bone Joint Surg Am 2005, 87:1761-1768.

12. Klepper SE: Measures of Pediatric Function: Child Health Assessment Questionnaire (C-HAQ), Juvenile Arthritis Functional Assessment Scale (JAFAS), Pediatric Outcomes Data Collection Instrument (PODCI), and Activities Scale for Kids (ASK). Arthritis Care Res 2011, 63:371-382.

13. Teixeira-Salmela LF, Magalhães LC, Souza AC: Adaptação do perfil de saúde de Nottingham: um instrumento simples de avaliação da qualidade de vida [Adaptation of the Nottingham Health Profile: a simple measure to assess quality of life]. Cad Saude Publica 2004, 20(4):905-914. 
14. Guillemin F: Cross-cultural adaptation and validation of health status measures. Scand I Rheumatol 1995, 24:61-63.

15. Beaton DE, Bombardier C, Guillemin F, Ferraz MB: Guidelines for the process of cross-cultural adaptation of self-report measures. Spine 2000, 25:3186-3191

16. Santos SV: Qualidade de vida em crianças e adolescentes com problemas de saúde: conceptualização, medida e intervenção [Quality of life in children and adolescents with health problems: conceptualization, measurement and intervention]. Psicologia, Saúde e Doença 2006, 7:80-94.

17. Pencharz J, Young NL, Owen JL, Wright JG: Comparison of three outcome instruments in children. J Pediatr Orthop 2001, 21:425-432.

18. Manners PJ, Bower C: Worldwide prevalence of juvenile arthritis: why does it vary so much? I Rheumatol 2002, 29:1520-1530.

19. Petty RE, Southwood TR, Manners P, Baum J, Glass DN, Goldenberg J, He X, Maldonado-Cocco J, Orozco-Alcala J, Prieur AM, Suarez-Almazor ME, Woo P: International League of Associations for Rheumatology classification of juvenile idiopathic arthritis: second revision, Edmonton, 2001. J Rheumatol 2004, 31:390-392.

20. Sawyer MG, Whitham JN, Roberton DM, Taplin JE, Varni JW, Baghurst PA: The relationship between health-related quality of life, pain and coping strategies in juvenile idiopathic arthritis. Rheumatology (Oxford) 2004, 43:325-330.

21. Klatchoain DA, Len CA, Terreri MTRA, Silva M, Itamoto C, Ciconelli RM, Varni JW, Hilario MOE: Qualidade de vida de crianças e adolescentes de São Paulo: confiabilidade e validade da versão brasileira do questionário genérico Pediatric Quality of Life Inventory ${ }^{\mathrm{TM}}$ versão 4.0 [Quality of life of children and adolescents in São Paulo: reliability and validity of the generic questionnaire, the Pediatric Quality of Life Inventory ${ }^{\mathrm{TM}}$, version 4.0.]. J Pediatr 2008, 84:308-315.

22. American Academy of Orthopaedic Surgeons (AAOS): POSNA/PODCI (Pediatric/Adolescent) Instruments. Reviewing and using the PODCI/POSNA (Pediatric/Adolescent) Outcomes Instruments 2003. [online] Illions; 2003. Available at: http://www.aaos.org/research/outcomes/outcomes_peds.asp Accessed December 22, 2010.

23. Schechter NL, Altman A, Weisman SJ: Report of the consensus conference on the management of pain in childhood cancer. Pediatrics 1990, 86:818-834.

24. Claro MT: Escala de faces para avaliação da dor em crianças: etapa preliminar. Dissertação (Mestrado em Enfermagem). Escola de Enfermagem de Ribeirão Preto da Universidade de São Paulo [Faces scale to assess pain in children: preliminary stage, Dissertation (Master in Nursing). Ribeirão Preto: Ribeirão Preto Nursing School of the University of São Paulo; 1993.

25. Wong DL: Enfermagem pediátrica: elementos essenciais à intervenção efetiva [Pediatric nursing: essential elements for effective intervention]. 5th edition. Rio de Janeiro: Guanabara Koogan; 1999:552-59.

26. Kwon DG, Chung CY, Lee KM, Lee DJ, Lee SC, Choi IH, Cho TJ, Yoo WJ, Park MS: Transcultural adaptation and validation of the Korean version of the Pediatric Outcomes Data Collection Instrument (PODCl) in children and adolescents. J Pediatr Orthop 2011, 31:102-106.

27. Assis TR, Forlin E, Bruck I, Antoniuk SA, dos Santos LH: Quality of life of children with cerebral palsy treated with botulinum toxin: are well-being measures appropriate? Arq Neuropsiquiatr 2008, 66:652-658.

28. Lopes AD, Ciconelli RM, Reis FB: Medidas de avaliação de qualidade de vida e estados de saúde em ortopedia [Measures of quality of life and the state of health assessment in orthopedics]. Rev Bras Ortop 2007, 42:355-359.

doi:10.1186/1471-2431-13-177

Cite this article as: do Monte et al: Validation of the Brazilian version of the pediatric outcomes data collection instrument: a cross-sectional evaluation in children and adolescents with juvenile idiopathic arthritis. BMC Pediatrics 2013 13:177.

\section{Submit your next manuscript to BioMed Central and take full advantage of:}

- Convenient online submission

- Thorough peer review

- No space constraints or color figure charges

- Immediate publication on acceptance

- Inclusion in PubMed, CAS, Scopus and Google Scholar

- Research which is freely available for redistribution

Submit your manuscript at www.biomedcentral.com/submit
C Biomed Central 